MICHEL GRAULICH

ÉCOLE PRATIQUE DES HAUTES ÉTUDES, PARÍS

UNIVERSITÉ LIBRE, BRUSELAS

\title{
El simbolismo del Templo Mayor de M éxico y sus relaciones con Cacaxtla y Teotihuacan ${ }^{\mathrm{I}}$
}

L SIMBOLISMO DE LA PIRÁmide MAYor de M éxico-Tenochtitlan es una fuente inagotable de especulaciones e hipótesis diversas, más o menos acertadas. En este artículo quiero comentar dos de estas especulaciones y sugerir que algunas otras de las ideas expresadas en el edificio eran muy antiguas y tenían antecedentes, no sólo en C acaxtla, sino posiblemente también en la antigua metrópoli de Teotihuacan.

Está de sobra decir que la pirámide mayor era doble y sostenía dos santuarios, uno dedicado al numen solar y otro al dios de la tierra y de la lluvia, T láloc. Sabemos desde el siglo xvi que la pirámide de H uitzilopochtli es el "Cerro de las Culebras", el Coatépetl, sobre el cual, al nacer, H uitzilopochtli-Sol ${ }^{2}$ mató a su (¿media?) hermana mayor y a sus hermanos mayores, los 400 Huitznahuas. Las fuentes, en particular Sahagún (II, Ap. I, I950-8I, 2: 175; también Tezozómoc, cap. 69, I878: 503) y sus informantes, lo mencionan explícitamente. Lo anterior permitió a Eduardo Seler (I9O2-I923, 2: 813I4), a principios del siglo, identificar correctamente una cabeza de Coyol-

I. Q uiero agradecer a mi alumno de la EPHE, G ustavo T orres, por la lectura crítica del texto en español.

2. U na fuente, por lo menos, dice casi explícitamente que $\mathrm{H}$ uitzilopochtli era el sol: Sahagún, $X, 2 \S_{4}$, quauhtlotli. 
xauhqui, encontrada en I829 cerca de la pirámide mayor, y relacionarla con el edificio estimando que debía estar colocada encima del Coatépetl, delante del santuario.

Las grandes excavaciones del Templo M ayor a partir de i979 y los hallazgos de ricas ofrendas relacionadas con Tláloc, todo combinado con el deseo de establecer un paralelismo entre el Coatépetl y el cerro de T láloc, inspiraron la idea de que la pirámide del numen telúrico y lluvioso era el Tonacaté petl, el cerro del maíz original del cual habla el mito (Leyenda de los Soles, p. 77). 3 Parece confirmar esta hipótesis el hecho de que las paredes interiores de la fachada del templo de Tláloc de la fase II estén decoradas con figuras del dios del maíz Centéotl, bien reconocible en un estilo códice muy acabado. Sin embargo, a mi juicio tal hipótesis debe ser rechazada porque según el mito, y según todas sus versiones modernas recogidas entre pueblos muy distintos, como los nahuas de la Sierra N orte de Puebla (Taggart 1983: 90) o los pipiles de EI Salvador (Schultze Jena 1935: 60, 345; Bierhorst 1990: 215), $\mathrm{N}$ anáhuatl hendió el cerro (con el rayo) y los Tlaloque robaron el maíz y otros alimentos. El Tonacatépetl fue, pues, vaciado en esta época y no tenía sentido representarlo en la pirámide de M éxico-Tenochtitlan. ${ }^{4}$ Además, ninguna fuente asocia la morada de T láloc o su templo con el Cerro del M aíz.

0 tra afirmación que debe ser matizada es que la gran pirámide era el axis mundi, "el centro del mundo azteca" o del mundo, o el "cerro del mundo" (Brundage 1985: 77; M atos M octezuma 1988: 123; Townsend 1992: 154; Read 1998: 9; Carrasco ı991: XVIII; Arnold 1999: 49). En primer lugar, no tenemos ningún texto que lo diga. Tenemos en cambio algunos indicios sobre el significado de las pirámides en general. No faltan los testimonios arqueológicos y escritos que indiquen que el techo del templo-casa del dios fuese concebido como la bóveda celestial (¿el décimo, decimosegundo o decimotercer cielo?). Ejemplos etnográficos sugieren también que los cuerpos super-

3. Véase, por ejemplo, T ownsend I992: 154.

4. El origen del error debe buscarse en una traducción dudosa de Zimmerman (citado en N owotny, 1970: 16), quien interpretó el pasaje de la leyenda como un robo del cual los T laloque serían las víctimas y no los autores. Pero, a pesar de un verbo pasivo poco ortodoxo, para los demás traductores del Códice Chimalpopoca (Lehmann, Velázquez y Bierhorst; véase también Garibay 1964: 28), son los T laloque los que se robaron el maíz. En cualquier caso el Tonacatépetl quedó vacío, ya no era el cerro de los alimentos y ya no había ningún motivo para que los T lal oque se instalasen en él. 
puestos simbolizaban los otros cielos o los escal ones ascendidos por el sol en su curso diario (K rickeberg 1950: 295-333). Esto parece plausible en algunos casos, pero es más difícil de aplicarlo a la gran pirámide de M éxico-Tenochtitlan que sólo contaba con cuatro cuerpos superpuestos. Lo más probable es que las pirámides fuesen montes artificial es que acercaban a los humanos con sus dioses en el cielo - y por lo tanto no necesariamente eran ejes del universo. Los gigantes de una edad anterior construyeron una pirámide para llegar al sol (D urán, H istoria, cap. I, 1967, 2: 17). M uchos cerros eran concebidos como dioses o por lo menos eran divinos, al gunos eran la morada de los T laloque y de otros seres sobrenaturales, sus cuevas eran entradas al inframundo. Eran también lugares escogidos de actuación o de materialización de dioses, como Q uetzalcóatl en el M ixcoatépec, o H uitzilopochtli en el Coatépec y el Tepetzinco (Tezozómoc 1949: 42). Los dioses vivían en sus cumbres al igual que sus imágenes en los santuarios encima de los montes hechos por los hombres: las pirámides.

La idea del axis mundi o "centro" o "cerro del mundo" viene, por su lado, en línea directa de los escritos de M ircea Eliade sobre los "simbolismos arquitectónicos del centro". Según él:

a) "el Cerro Sagrado - donde se juntan Cielo y Tierra - está en el centro del mundo;

b) todo templo o palacio - y, por extensión, toda ciudad sagrada o residencia real - es una "montaña sagrada" y se vuelve así un centro;

c) siendo un axis mundi, la ciudad o un templo sagrado son considerados como el punto de unión entre el Cielo, la Tierra y el Infierno" (Eliade i969: 17; 1970: 316-20; 1965: 34-46).

En realidad, Eliade generaliza a partir de un cierto número de casos, como suele hacerlo. Sus generalizaciones pueden ser útiles como modelos de interpretación pero siguen siendo meras posibilidades si no pueden sustentarse con datos entresacados de la cultura examinada. Ahora bien, que yo sepa, tales datos hacen falta para los aztecas. ¿Cuáles son los textos que ubican a M éxico, el Templo M ayor o la gran pirámide en el centro del mundo? Todos los argumentos que pudieran aducirse para probarlo valdrían igualmente para cualquier otra pirámide principal de cualquier otro recinto sagrado en cualquier ciudad. El imperio azteca - una confederación - no era (todavía) lo bastante centralizado, tampoco desde el punto de vista religioso, para poder reivindicar más que otras grandes ciudades el estatuto de centro del mundo. 
$\mathrm{H}$ ay otras dificultades. Si el recinto sagrado de M éxico-Tenochtitlan era el centro de la ciudad - el lugar donde se encontraban las cuatro calzadas orientadas hacia los cuatro rumbos del universo- y el centro del mundo, la gran pirámide no podía serlo también, ya que no estaba en el centro del recinto. El plano de un recinto sagrado en los Primeros memoriales, las descripciones del recinto de Tenochtitlan y el trazo posterior de la ciudad muestran claramente que la gran pirámide estaba al este del punto de convergencia de las calzadas. Si en cambio era la pirámide el centro y no el recinto, y si era al mismo tiempo un axis mundi, ipor dónde pasaba el eje, por la pirámide de Tláloc, la de H uitzilopochtli o la de los dos? ¿O era un "eje" doble? ¿Y qué hacer con el otro recinto sagrado, el de T latelolco, con una gran pirámide no menos desarrollada y con tantas fases de construcción como la de Tenochtitlan? ¿También era un centro-eje del mundo?

Todo esto nos lleva a constatar otra vez la importancia del dualismo, de la bipolaridad, incluso en el antiguo islote. Creo que podemos estar en lo cierto al decir que esta isla de M éxico (xic-, ombligo) fue considerada como un centro: centro de la laguna, centro del valle, y probablemente centro del imperio. Pero este centro era una unidad de opuestos, con dos ciudades, $\mathrm{Te}$ nochtitlan y T latelolco, dos grandes recintos o Templos $M$ ayores, y en cada Templo M ayor otra unión de los contrarios: una gran pirámide hecha de dos templos dedicados al sol (H uitzilopochtli) y a la tierra-agua (Tláloc). Esta bipolaridad hace eco de la bipolaridad generalizada subyacente en toda la cosmovisión mesoamericana y en particular en la azteca. U na bipolaridad dada, desde el origen, con el principio creador, la bien Ilamada pareja 0 metecuhtli-O mecíhuatl, el Señor y la Señora D os, una pareja que forma una unidad (O metéotl), pero que resume en sí las polaridades del universo: masculinofemenino, activo-pasivo, fuego-agua, caliente-frío, luz-tinieblas, sol-tierra 0 luna, día-noche, estación seca (equiparada al día)-estación de lluvias (nocturna), guerrero-agricultor, etc. U na bipolaridad que se refleja también en el gobierno de la ciudad, con el tlatoani como representante del Sol-H uitzilopochtli-Cielo Azul, y el cihuacoatl que encarna a la diosa telúrica cuyo nombre lleva. Un dualismo, en fin, que caracteriza también a las dos ciudades gemelas: Tenochtitlan es la ciudad solar, mientras que T latelolco, en cambio, es claramente designada como lunar. No es necesario insistir sobre la "solaridad" de Tenochtitlan, ciudad del águila solar que devora la serpiente, símbolo de la tierra, de la noche, de los autóctonos..., ciudad del nopal, "árbol" solar de las tierras secas, de la diurna estación seca, nopal que surge de la la- 
guna que simboliza la estación nocturna de lluvias. Tlatelolco, en cambio, fue supuestamente fundada después de Tenochtitlan: la luna corre siempre detrás del sol sin nunca al canzarlo. Su antiguo nombre habría sido Xaltilolco (Chimalpahin, Tercera relación, f. 8IV, año I337) y el xalli, la arena, está asociado con la luna y el T lalocan ubicado en ella (Códice Vaticano A, f. 2). Los xal tocanecas adoraban a la luna. El nombre de su primer rey habría sido Epcóatl, epíteto de Tláloc. D urante las migraciones, cuentan los mitos, dos envoltorios caen del cielo. Los tlatelolcas escogen el que contiene una piedra verde símbolo del agua, mientras que los mexicas, no dejándose engañar por la aparente riqueza, toman el otro envoltorio con los palillos para encender fuego, un instrumento ofrecido en el Códice Boturini por el mismo H uitzilopochtli-Sol bajo la apariencia de un águila.5 Por fin, los eventos de la conquista de Tlatelolco por Tenochtitlan también contienen varios elementos simbólicos que ilustran el papel lunar de la ciudad vencida (Graulich I990: 265-67 0 1997: 246-47).

$\mathrm{H}$ ablando de ejes del mundo, quisiera añadir algunas palabras sobre los árboles como ejes cósmicos y en particular sobre el supuesto árbol del centro de la tierra. Aquí también, el texto más claro habla de los dos árboles en los que se metamorfosearon Q uetzal cóatl y Tezcatlipoca para ayudar a los cuatro "hombres-fechas calendáricas" a sostener la bóveda celeste en el principio del Sol actual (Teogonía e historia de los mexicanos por sus pinturas 1965: 32). En los ritos también se erigían dos árboles para sostener al cielo, uno (teóricamente) al final de la temporada de lluvias, en atlcahualo, y el otro al fin de la estación de lluvias, en xocotl huetzi. Es posible que a veces se representara a estos árboles como entrelazados. ${ }^{6}$ En ciertos códices figuran también posibles árboles de las cuatro esquinas del mundo, como en el Códice Borgia (pp. 49-52) 0 en el Códice Vaticano B (pp. I7-I8). El supuesto "árbol del centro" del Borgia (p. 53; ausente en el Vaticano A) es, en cambio, una planta del maíz que, a diferencia de los árboles verdaderos, es presentado como el resultado del autosacrificio y no necesariamente como sostén del cielo. El único árbol-eje azteca que me parece convincente es el de Tamoanchan, en el sentido de que simboliza la unión, el contacto entre los creadores y las criaturas. Pero según los mitos, este árbol del paraíso inicial se rompió por una trans-

5. D ebo la información a Patrick Johansson.

6. Como se entrelazaron $Q$ uetzal cóatl y $M$ ayáhuel transformados en árboles en un mito de la Teogonía ehistoria de los mexicanos (1965: I07). 
gresión que dio en el origen del mundo actual. Se le suele representar roto, y cuando se le figura intacto es cuando se alude al paraíso perdido o cuando se representan ritos que reactualizan los eventos del paraíso perdido (por ejemplo, los ritos de atamalcualiztli en los Primeros memoriales de Sahagún o de atlcahualo en D urán (1967, I: 86 y lám. I4), quien habla equivocadamente de huey tozoztli. 7

Volvamos a la gran pirámide del Templo M ayor y a su duplicidad. Al sur, la morada de Huitzilopochtli y, al norte, rumbo del inframundo, la de Tláloc: el templo del sol y de los guerreros presentados como recién llegados y el templo de los agricultores autóctonos. Un episodio de la fundación de Te nochtitlan ilustra bien la oposición autóctonos-recién llegados: un sacerdote mexica es atraído a la laguna por el autóctono por excelencia, T láloc, quien da la bienvenida a su hermano H uitzilopochtli (Códice Aubin ff. 24-25). ${ }^{8}$ Se simbolizaba aquí también, como lo observó muy acertadamente $\mathrm{M}$ atos M octezuma (1986: 8I-82), las dos bases económicas de los mexicas: la agricultura y la guerra que produce el tributo. Ahora bien, la única base conservada del edificio, la de la fase IVb, está rodeada de cabezas de serpientes. Éstas podrían por supuesto aludir al hecho de que la pirámide era el Coatépec, el Ce-

7. La idea según la cual es por árboles cósmicos, entrelazados o no, por donde pasan los hipotéticos flujos fríos y calientes que vitalizan al mundo es interesante y sugerente, pero me parece que necesita más estudios y análisis más pormenorizados. Q ue yo sepa, no tenemos ningún texto que aluda a eso, y el mito del rompimiento del árbol de Tamoanchan parece estar en contradicción con dicha interpretación. $\mathrm{N}$ o veo muy bien qué sugiera una restauración del árbol roto al principio de una nueva edad: al contrario, el rompimiento señala el exilio de las criaturas sobre la tierra en donde sólo el sacrificio, es decir la muerte aceptada, permite restablecer el contacto de los dioses con la pareja primordial o de los hombres con los dioses. Tampoco tenemos datos que, como los vedas de la India o la mitología germánica o escandinava (Yggdrasil) señalados por Eliade (1970: 236-8), describan al cosmos como un árbol, si bien Eliade aduce datos sugerentes que hacen pensar en T enochtitlan, como cuando menciona, al pie del árbol Yggdrasil, la presencia de una víbora que intenta desarraigarlo y, en la cima, la de un águila que cada día lucha contra ella.

8. La oposición guerreros-recién llegados se destaca también en la escultura de los templos. D elante del santuario de Tláloc (fase II) se observa un Chac M ool ricamente ataviado con los adornos típicos del dios como se figuran en el Códice Borbónico (p. 7). La otra piedra de sacrificio, enfrente del santuario del Sol, en cambio, es una austera piedra trapezoidal sin decoración al guna. El contraste entre los dos corresponde al mismo que caracteriza, por un lado, los códices "históricos" de las migraciones mexicas, como el Boturini, voluntariamente arcaicos para reflejar el modo de vida sencillo y austero de los nómadas migrantes; y por el otro los ricos códices sacerdotales policromados de los autóctonos de tradición cultural mesoamericana. 


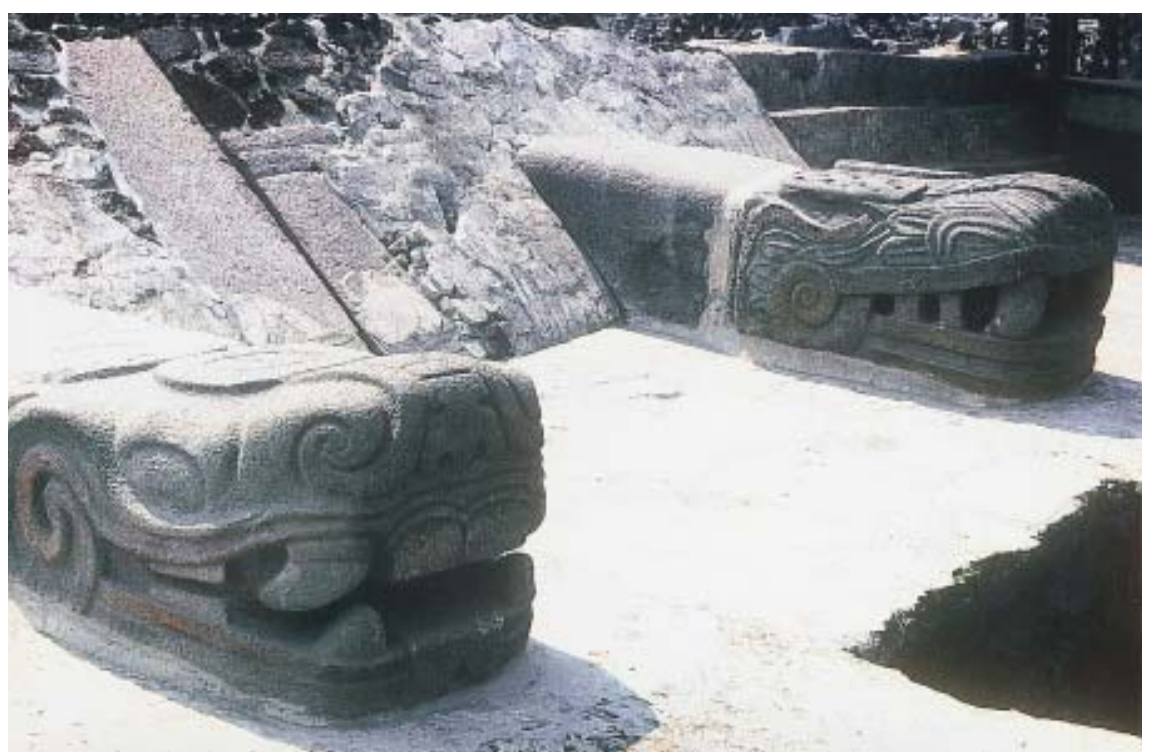

Figura I. Serpientes de la fachada de la pirámide de T láloc y H uitzilopochtli, fase IVb, T emplo M ayor, T enochtitlan. Foto: M ichel Graulich.

rro de la Serpiente, pero esta explicación no puede ser la única, porque la base de la pirámide de T láloc (unida a la de H uitzilopochtli, aunque en principio distinta) también ostenta estas cabezas y porque otras pirámides, como la de Tenayuca, también están rodeadas de serpientes. Lo interesante es que en la fachada principal (y probablemente en la posterior) las serpientes del lado de H uitzilopochtli y de T láloc son diferentes (figura I). Al sur, son serpientes emplumadas con ojos alargados y sobrecejas con motivos de estera, mientras que a las del norte les faltan las plumas pero están decoradas con dos círculos, como "anteojeras" de Tláloc, sobre la cabeza. La serpiente con anteojeras remite claramente al dios de la lluvia y de la tierra. El simbolismo de la otra es más complejo. Primero, es el nahualli, el doble sol: representa al cielo azul - xoxauhqui ilhuicatl, epíteto de Huitzilopochtli- que acompaña al astro

9. La palabra para azul y verde (como las plumas de quetzal) era la misma en náhuatl: xoxauhqui. La serpiente emplumada simboliza al cielo diurno: las plumas de quetzal que forman una bóveda sobre la tierra eran una metáfora para designar al cielo (Sahagún i950-8I, 6: II3). Los quichés créan que la serpiente emplumada levantaba el sol hacia el cielo y, en la tar- 
diurno. ${ }^{9}$ Luego, se refiere a Q uetzalcóatl de Tollan como fuente de todo poder legítimo, este dios sobre $\mathrm{el}$ asiento - tepetlatl, literalmente, estera de piedra, y trono, icpalli- del cual fue fundado Tenochtitlan (Tezozómoc 1949: 43) y cuyo templo fue el primero construido en la ciudad (Tezozómoc i878: 23I). El motivo de estera de las serpientes emplumadas, otro símbolo de poder, alude por supuesto también al tepetlatl y al icpalli. El hecho de que el edificio descanse sobre serpientes emplumadas es ambiguo: legitima el poder mexica, pero al mismo tiempo expresa cómo el nuevo dios Huitzilopochtli sobrepasó y sustituyó al antiguo, como lo hizo también en las fiestas de las veintenas, en donde $Q$ uetzal cóatl fue sistemáticamente reemplazado por el colibrí zurdo.

0 tros detalles pueden señalar la oposición entre el lado norte oscuro, nocturno, de la temporada de lluvias - de Tláloc- , y el lado sur diurno. D ebajo de la piedra de sacrificios del templo del sol de la fase ll los arqueólogos encontraron cinco cuchillos de pedernal, mientras que debajo de la piedra de sacrificios en forma de $C$ hac $M$ ool del lado norte había cinco cuchillos de obsidiana. Ahora bien, el pedernal es de origen celeste mientras que la obsidiana viene del interior de la tierra; el simbolismo del primero lo asocia con la estrella de la tarde y la semilla de maíz que penetran, ambos, en la tierra desde lo alto, mientras que la obsidiana, oriunda del interior de la tierra, corresponde a la mata tierna del maíz que acaba de nacer y a la estrella de la mañana que también sale de la tierra. En los ritos, Cintéotl-O bsidiana retorcida nacía en ochpaniztli, el primer mes de la estación de lluvias; era al mismo tiempo el nuevo brote de maíz y la estrella de la mañana que nacían de Toci, $N$ uestra Abuela, la diosa Tierra. (C abe añadir que los ocho días, más o menos, que separan la siembra de maíz del nacimiento de la planta correspon-

de, Io llevaba al océano (C armack I98I: 275). La estatuilla de Stuttgart representa a T lahuizcalpantecuhtli llevando a cuestas una serpiente emplumada con la imagen del sol: la estrella de la mañana abre el camino y porta al sol y al cielo azul. En fin, también en el cofre de H ackmack ( $M$ useum für Volkerkunde, $\mathrm{H}$ amburgo) la serpiente emplumada representa al sol. Prueba de ello es el hecho de que el cofre sea concebido como una imagen del universo. En la superficie inferior, en contacto con la tierra, encontramos una imagen del monstruo de la tierra. Al interior, en el fondo, un cipactli, otra invocación de la tierra. La tapa en cambio representa al cielo. Al exterior - es decir en la luz- , una serpiente emplumada, el cielo diurno. Al interior del cofre, y por lo tanto en las tinieblas, una calavera y ojos estelares que se refieren a la noche. (Lo anterior me obliga a mencionar que estas interpretaciones contradicen a las de Pasztory I984.) 
den a los ocho días de invisibilidad de Venus después de su desaparición como estrella de la tarde y antes de su surgimiento como estrella matutina.)

La oposición entre serpientes vuelve a encontrarse en la pirámide de Tenayuca, donde las serpientes del lado sur eran (Tenayuca 1935: 246) de color predominantemente azul y las del norte negras. Tal antagonismo se remonta por lo menos al siglo viII, como lo prueban los murales del Edificio A de Cacaxtla ( $T$ laxcala), pintados en estilo maya de fase dinámica (750-8Io), pero sin glifos mayas, lo cual se explica por el hecho de que el público, es decir la población autóctona, debía ser predominantemente no maya. En cambio hay bandas acuáticas y glifos de tradición teotihuacana y del altiplano mexicano.

Situadas a ambos lados de un pórtico, las pinturas del Edificio A muestran a dos majestuosos reyes. El rey del muro sur - lado solar - , típicamente maya a juzgar por su perfil, sus atavíos y su barra ceremonial, está disfrazado de águila (figura 2). Su nombre calendárico es iz Pluma, es decir i3 $C$ aña, nombre del sol entre los aztecas (por ejemplo en la Piedra del Sol).. ${ }^{\circ}$ Está de pie sobre una serpiente de plumas azules cuyo cuerpo se yergue a su lado como si fuera su doble o nanahualli:"I representa al cielo o al horizonte diurno, nahualli del sol. Del lado nocturno o norte, en cambio, tenemos un rey del altiplano mexicano ${ }^{12}$ disfrazado de jaguar, el animal telúrico por antonomasia (figura 3). ${ }^{3}$ Lleva un haz de flechas a guisa de barra ceremonial, ya que este último emblema de poder no existía en el altiplano mexicano. D e las puntas de obsidiana de las flechas caen gotas de agua que aluden a la estación de llu-

Io. Entre los aztecas el glifo caña es figurado a menudo con plumón y una pluma. Véase por ejemplo el cofre H ackmack (nota 8). En náhuatl, se llamaba totolacatl, "caña de ave", al cañón o cálamo de la pluma (M olina i970: 150), y es muy probable que en Cacaxtla se hablara náhuatl, como veremos más adelante. En este caso, la sustitución de la caña por una pluma de águila debe acentuar la relación entre el nombre calendárico y el personaje águila.

II. La palabra se usa también para los dobles o acompañantes animales, por ejemplo en la descripción de los atavíos de los dioses por los informantes de Sahagún.

I2. Su carácter autóctono puede deducirse del hecho de que no lleva barra ceremonial, del perfil (muy diferente del perfil maya, a veces exagerado casi hasta la caricatura en las pinturas de ( acaxtla) del corte de cabello de su acompañante jaguar y de los adornos para las piernas de ambos personajes, que se vuelven a encontrar en los vencedores de los mayas en la escena de batalla).

13. El jaguar era el animal del Sol de Tierra y un aspecto de Tezcatlipoca - hermano y opuesto de Q uetzalcóatl-Serpiente Emplumada - representado como serpiente-jaguar en una escultura del M useo Etnográfico de Berlín. Según Alarcón (I984: I8I), I Jaguar era el nombre esotérico del cuchillo de obsidiana. 


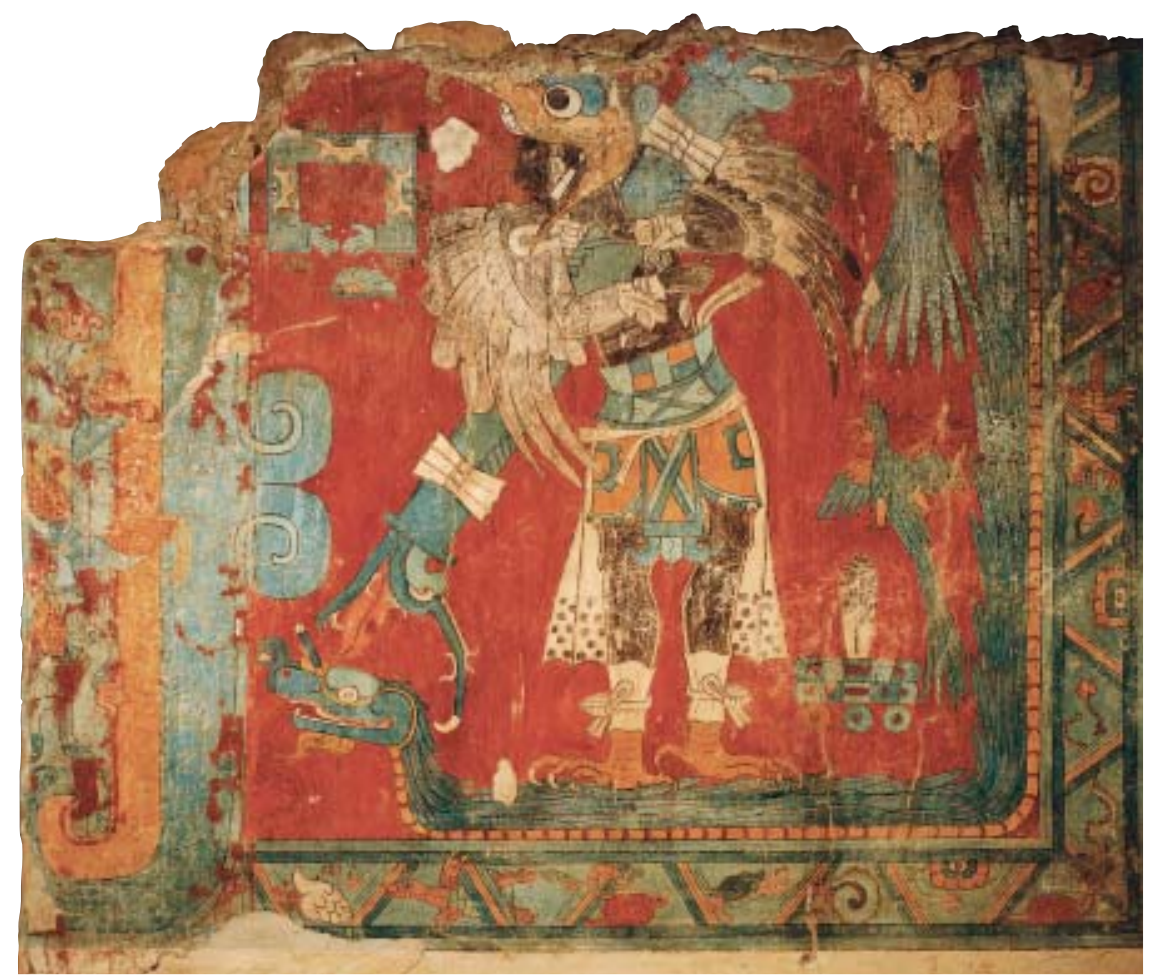

Figura 2. "El gobernante solar", M ural Sur del Edificio A, Cacaxtla. Foto: Eumelia H ernández y G erardo Vázquez, Archivo Fotográfico IIE-UnAM.

vias, nocturna. Su nombre es , Ojo de Reptil o 9 Viento, nombre cuyas connotaciones nocturnas y telúricas son de sobra conocidas. Era el nombre azteca de Venus; en la veintena de atlcahualo, 9 Viento era sacrificado a medianoche; y Ehécatl estaba asociado con las Iluvias y con los T laloque. Los "pequeños Ehécatl", ehecatotontin, eran considerados como T laloque-vientos que barrían el camino para la lluvia. El tocado cónico de Ehécatl era de piel de jaguar y a 9 Viento a veces se le figuraba con bocas en las coyunturas, como a las deidades telúricas (Sahagún 1950-8I, 1: 47; 2: 187; Códice Borgia, p. 56). El rey-jaguar está acompañado de una serpiente-jaguar con patas anteriores, obviamente también su alter ego. La obsidiana de sus flechas contrasta con el pedernal que sale del hocico de la cabeza de serpiente que remata la barra ceremonial del rey solar. Se marca aquí también, aunque 700 años 


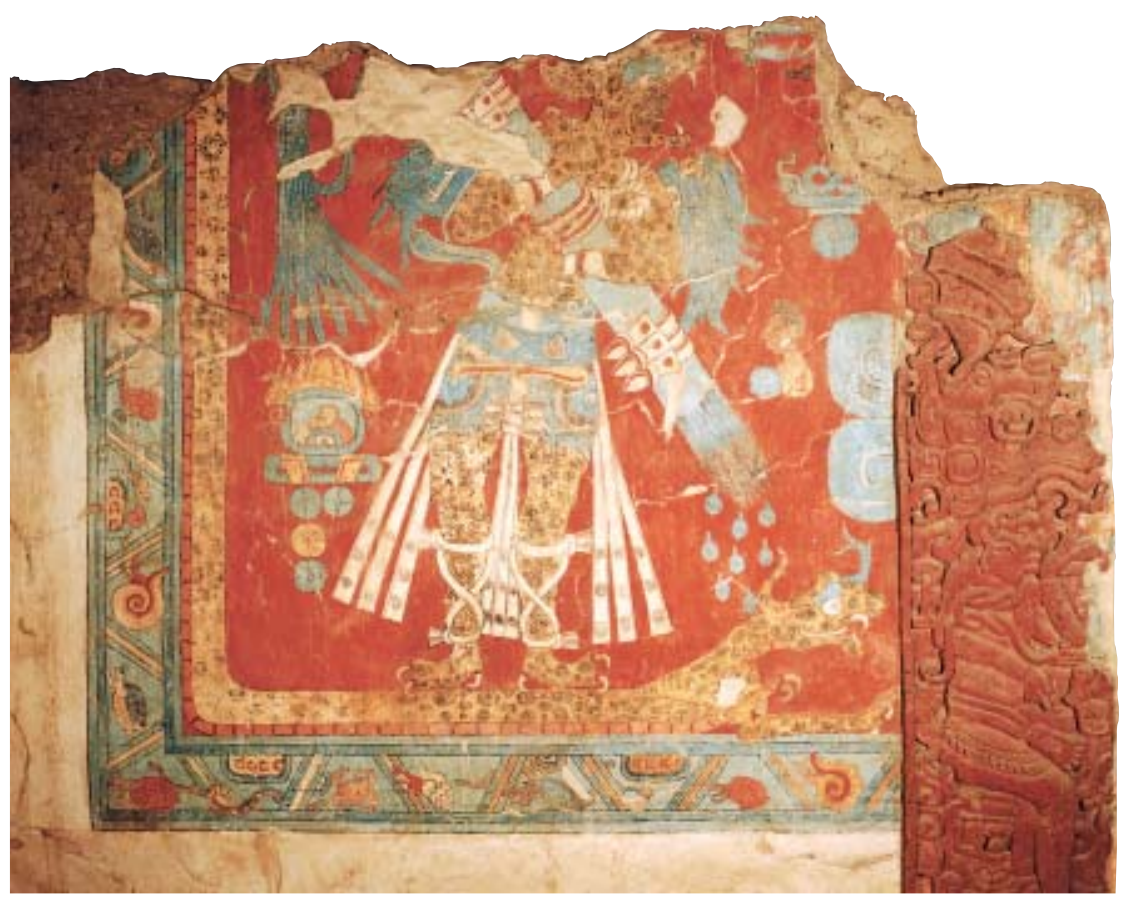

Figura 3. "El rey telúrico-nocturno", M ural N orte del Edificio A, Cacaxtla. Foto: Eumelia

antes que los aztecas, la oposición entre norte y sur, temporada de lluvias y temporada de secas.

Los dos personajes corresponden al rey y al cihuacóatl del Posclásico tardío. Sabemos por las fuentes que, desde el siglo viri 0 ix, el gobierno de los olmeca-xicalanca de esta zona era bicéfalo; uno de los gobernantes estaba simbolizado por un águila y el otro por el jaguar (Rojas 1985: 129-31; M uñoz Camargo 1984: 247-48; H istoria tolteca-chichimeca ff. 8V, 9V, 1976: I49-150). Los murales de Cacaxtla ilustran también que el rey maya pertenecía a los conquistadores recién llegados, mientras que el rey-jaguar era el autóctono. En la escena de batalla, los mexicanos están sistemáticamente asociados con el jaguar y, además, con T láloc.

Las referencias a las estaciones están claramente confirmadas por la iconografía de las jambas del pórtico. D el lado del rey-jaguar autóctono encontramos otro personaje disfrazado de jaguar que está vertiendo agua de una vasija 
decorada con una cabeza de Tláloc (figura 4). En su mano (o garra) blande una serpiente decorada con una flor y al gunos elementos que sugieren nubes. (En la iconografía posclásica, e incluso en el pensamiento de los indios de hoy, las serpientes simbolizan el rayo fertilizante: Códice B orbónico, pp. 7, 24, 29; Ichon 1969: I2I-I22; en la pintura de Teotihuacan: M iller 1973: I26.) De su ombligo nace una planta joven de maíz todavía sin mazorcas pero con flores de maíz imaginarias (Polaco i986: 534; Kubler 1980: 170). Debajo de la planta joven se ve su nombre calendárico: 7 O jo de Reptil, es decir 7 V iento ("ojos de reptil" adornan también las "faldas" de los dos personajes-jaguares).

Al lado sur, en cambio, 3 Venado, el compañero del rey-águila, es claramente maya (figura 5). Su falda y sus sandalias son de piel de jaguar. Lleva el cabello largo que cae hasta el suelo y en los brazos tiene una gran concha (Strombus gigas) de donde sale un individuo también de largo cabello rojo debajo del cual encontramos otra vez el glifo 7 Viento. Tomando en cuenta que $7 \mathrm{~V}$ iento es el nombre del maíz en la jamba norte, y que en el tablero de la Cruz foliada de Palenque una planta de maíz con mazorca sale también de una concha, el individuo 7 Viento saliendo de la concha - símbolo de la matriz y de la vidai4- debe ser el maíz 0, mejor dicho, la mazorca de maíz duro. D e ahí su largo cabello rojo que lo cubre, como la barba roja que cubre a la mazorca. 3 Venado aparece, pues, como el segador, asimilado en parte con su cosecha, como lo señala su largo cabello con flores de maíz. Su nombre está ausente en las fuentes posclásicas, pero por lo menos sabemos que la cifra 3 era considerada como buena y como signo de posible prosperidad (Sahagún i950-8I, 4: 70). En cuanto al día Venado, su regente es T láloc y es un símbolo de sequía y de fuego. ${ }^{\text {Is }} \mathrm{El}$ venado era también la caza por excelencia $y$, como tal, el equivalente animal del guerrero enemigo. ${ }^{16}$ Los guerreros heroicos eran compañeros del sol, y en el Códice Borgia ( $p .33$ ) se representa al venado como portador del sol. Todo eso compagina bien con la cosecha, que se sitúa

I4. M atriz: Códice Vaticano A, lám. 26, p. 69. La concha es símbolo de Ehécatl en cuanto dios que da el soplo vital al recién nacido. Se equipara también al hueso, que es a la vez muerte y principio de vida puesto que los huesos son semillas, como los huesos de las frutas.

I5. Los mixes asocian también al venado con el arcoiris, sol-Iluvia: cuando sale, es porque una venada está alumbrando (agradezco a G ustavo T orres por la información).

I6. Según G. T orres, todavía se conserva esta ideología en los pueblos actuales, la del venado como la presa por antonomasia; en algunos lugares del campo mexicano matar a un enemigo se llama "venadear" en español y mucho se usó esta expresión en los conflictos caciquiles de los mixes. 
DOI: http://dx.doi.org/10.22201/iie.18703062e.2001.79.2086

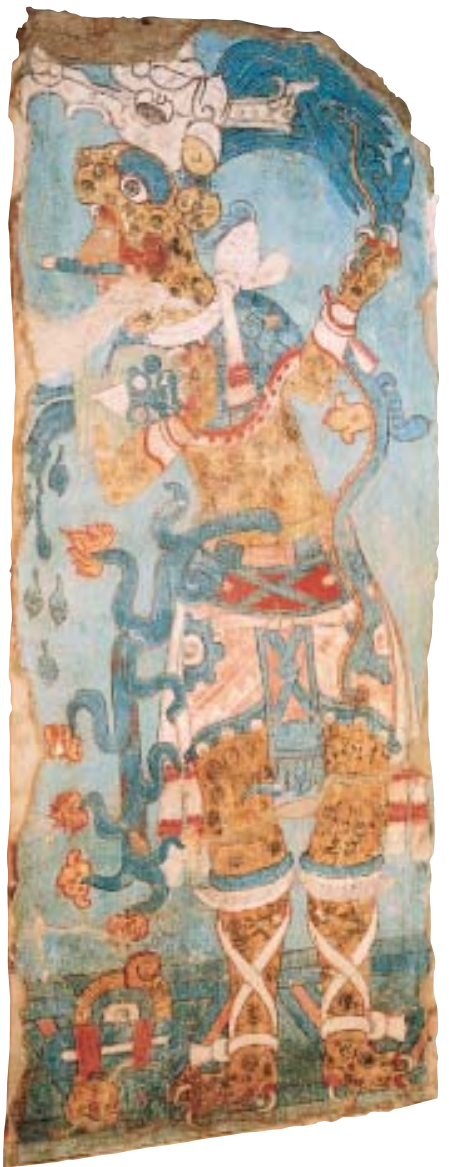

H ernández y G erardo Vázquez, Archivo Fotográfico IIE-UnAM.

Figura 4. "H ombre-jaguar", Jamba N orte del Edificio A, Cacaxtla. Foto: Eumelia

H ernández y Gerardo Vázquez, Archivo Fotográfico IIE-UNAM.

Figura 5. "Glifo de 3 Venado", J amba Sur del Edificio A, Cacaxtla. Foto: Eumelia

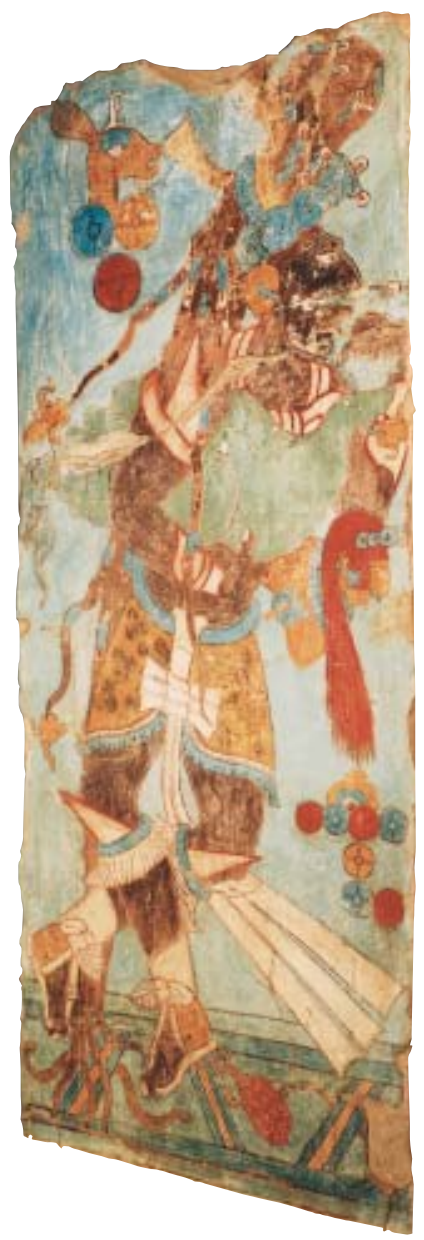




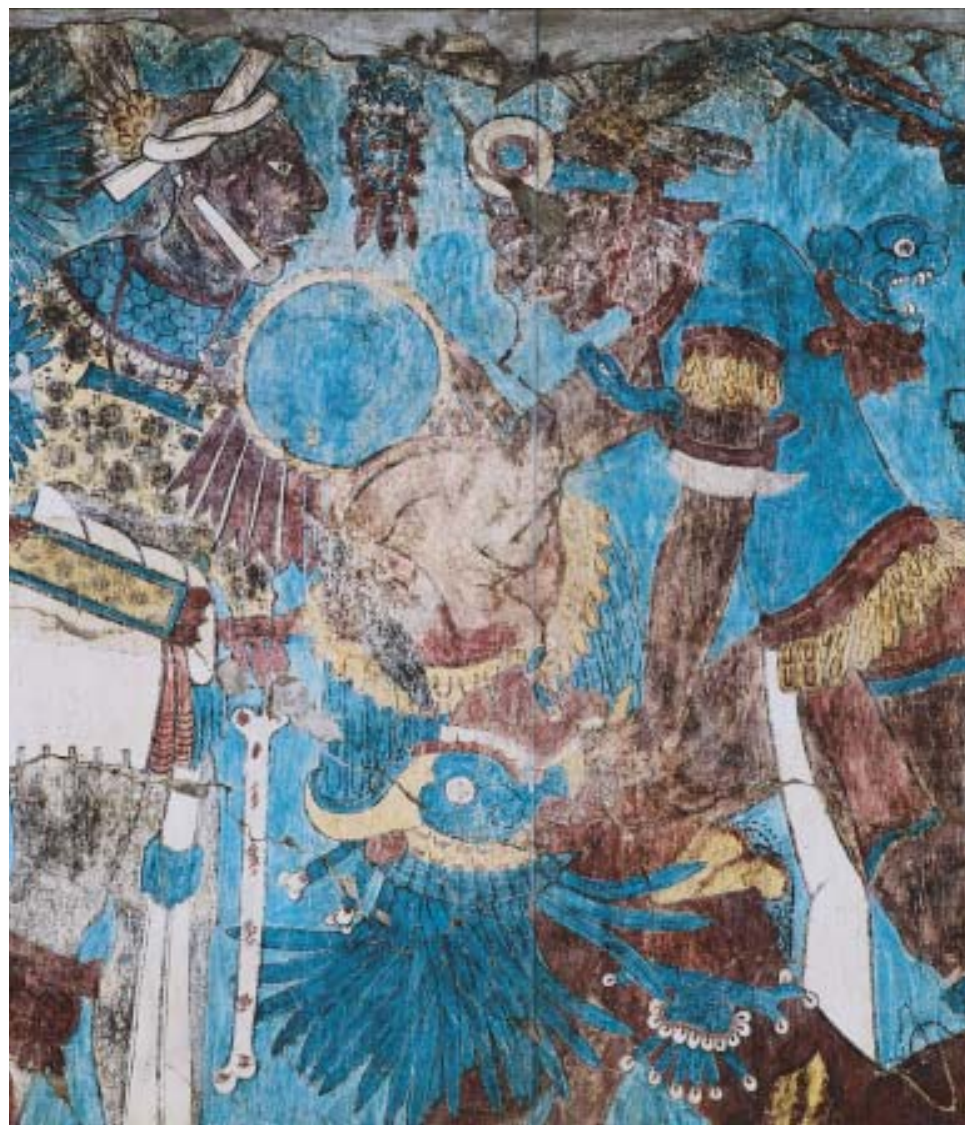

H ernández y G erardo Vázquez, Archivo Fotográfico iIE-unam.

Figura 6. Fragmento del "M ural de la batalla", Edificio B, T alud O riente, C acaxtla. Foto:

al principio de la estación seca, que era doble, puesto que ésta era también la estación de la guerra, cosecha de hombres para alimentar a los dioses. En el posclásico, tlacaxipehualiztli era la fiesta de la cosecha para los hombres (el maíz) y para los dioses (cautivos) a la vez (Graulich 1982; 1999: 279-320).

Figurado del lado del sol, el sur, aunque vestido con piel de jaguar, 3 Venado es ante todo un mediador entre los términos opuestos, como lo es también el maíz que nace al principiar la noche (estación de lluvias), pero cuyas mazorcas cosechadas al comienzo del día (estación seca) servirán también para la siembra del año siguiente. Es tanto más un mediador en cuanto que, 


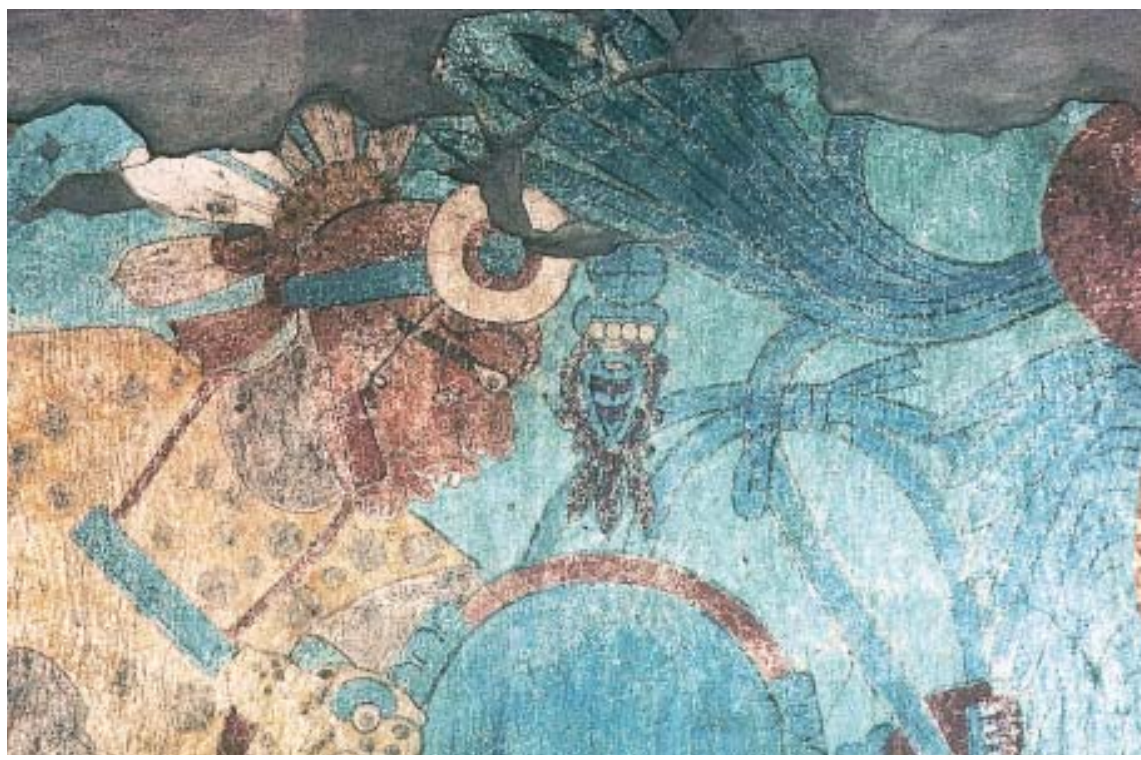

Archivo Fotográfico IIE-UnAM.

Figura 7. Fragmento del "M ural de la batalla", Edificio B, Talud Poniente, Cacaxtla. Foto:

plasmado aquí con rasgos mayas, 3 Venado aparece dos veces en el mural de la batalla del Edificio B como jefe de los autóctonos del altiplano.

El largo mural de la batalla es anterior a las pinturas del Edificio A y representa, siempre en estilo maya muy dinámico, ${ }^{17}$ una derrota maya ante los autóctonos (figura 6). Éstos están todos de pie, mientras que la gran mayoría de los vencidos yace en el piso. La oposición autóctonos telúricos versus invasores solares es expresada también aquí de manera sistemática: los primeros visten pieles de jaguar o símbolos de Tláloc, mientras que los otros llevan grandes tocados en forma de aves de grandes plumas verdes. Los adornos geométricos, la pintura facial, el corte del cabello, la extracción, por un autóctono, del corazón de un vencido y los escudos con franjas en cola de golondrina del tipo Xipe Tótec - dios relacionado con el maíz y la cosechaevocan fuertemente el altiplano y prefiguran a los aztecas. Además, varios autóctonos tienen distintos glifos de nombres y todos comparten glifos que de-

I7. Y además, cosa casi única en M esoamérica, representación de muecas de dolor o de gritos de rabia. 


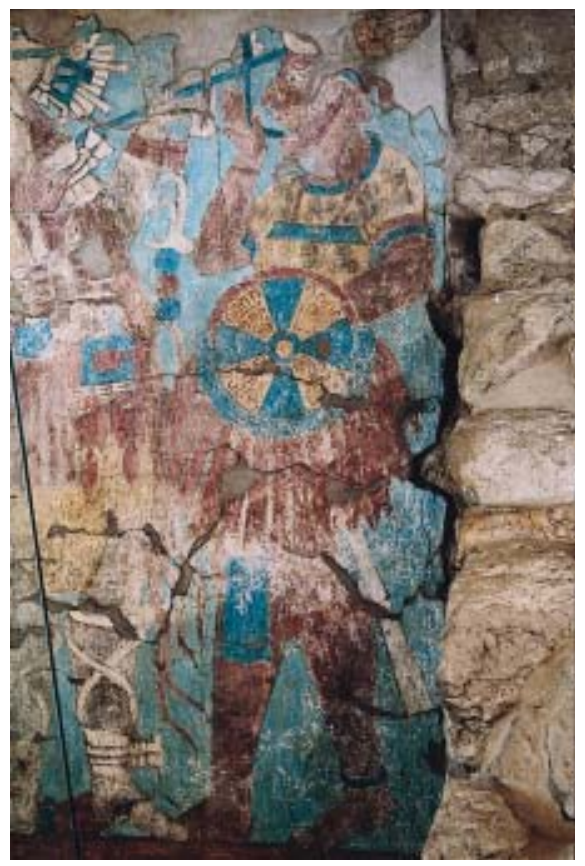

M ichel G raulich.

Figura 8. Fragmento del "M ural de la bataIla", Edificio B, Talud Poniente, Cacaxtla. Foto: Eumelia H ernández y G erardo Váz-

ben indicar su ciudad de procedencia y tal vez su grupo o su pueblo (figura 7). Lo que considero como el glifo de la ciudad se compone de un círculo dividido en cuatro partes encima de lo que parece una encía con cuatro dientes. El círculo cuatripartito suele referirse a la turquesa (xiuitl), mientras que en los códices aztecas, como el $M$ endocino, los dientes, tlantli en náhuatl, de ben indicar por homofonía el sufijo locativo - tlan, homofonía que, está de más decirlo, sólo funciona en náhuatl y sugiere otra vez, después de la pluma-caña, que los autóctonos eran nahuas. ${ }^{18} \mathrm{El}$ posible glifo del grupo 0 de la nación sería el "corazón sangrante" que acompaña al glifo anterior. Ahora bien, el jefe de los vencedores, figurado dos veces, se llama 3 Venado (figura 8)

18. Véase Graulich (1983: 92; 1990b: 107). La ciudad se Ilamaría algo como Xiuhtlan. El glifo se encuentra también en la pirámide de la serpiente emplumada de Xochicalco. Sabemos por la Historia tolteca-chichimeca, ff. 25-27, que Xiuhcalco era uno de los nombres de Cholula. El glifo "corazón sangrante" se encuentra en la estela 3 de Xochicalco, pero también, por ejemplo, en el taparrabo del rey figurado en la estela 6 de Copán (682), rey que en su tocado lleva máscaras de Tláloc y el glifo mexicano del año. 

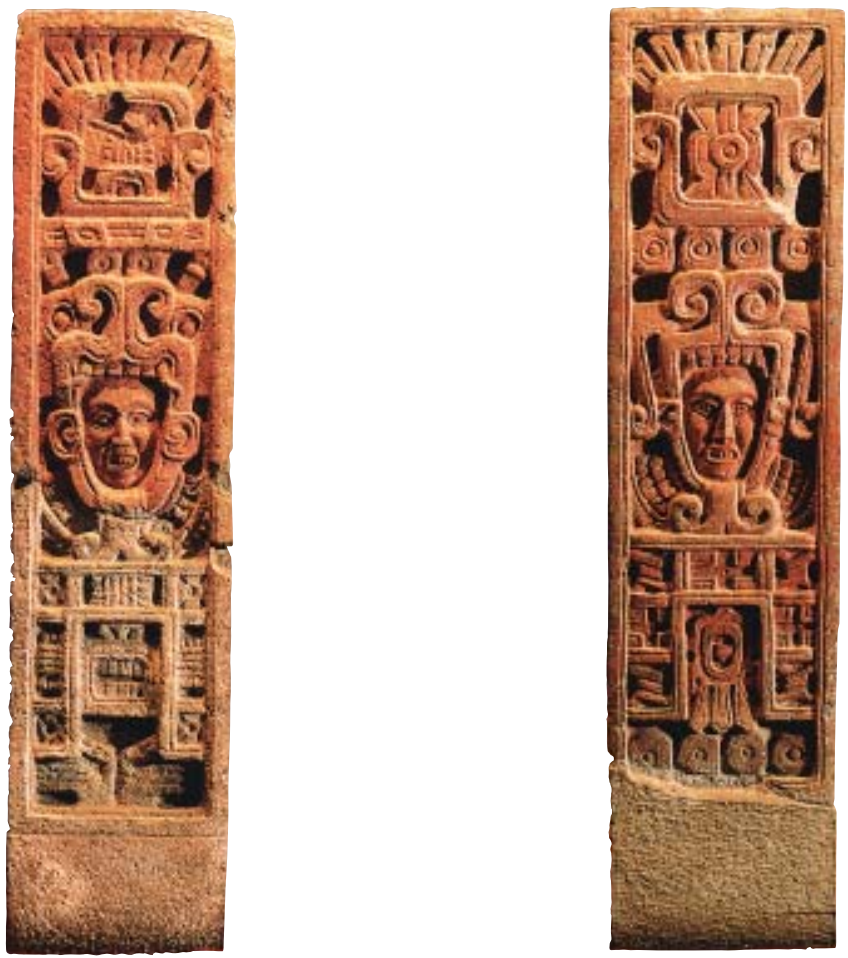

quez, Archivo Fotográfico IIE-UnAm.

y lleva cabellos largos hasta el piso: es el segador, esta vez no del maíz, sino del pan de los dioses que son los enemigos. Lleva una máscara de T láloc sobre la cara, y en una de sus dos representaciones observamos también un gran tocado esférico decorado en la frente con una roseta de papel como la de los dioses de la muerte en el Posclásico. Su procedencia de Xiuhtlan está indicada no por el glifo antes descrito, sino por el glifo del año (también xiuitl ) en el tocado. En el pecho ostenta un adorno que parece evocar el pecho abierto del sacrificado y la sangre que brota del mismo. (Reyes con adornos y tocados equiparables están representados en las estelas 2 de Aguateca y i6 de $D$ os Pilas.)

Para concluir sobre $C$ acaxtla: tenemos aquí una ilustración extraordinaria del gobierno bicéfalo y de su ideología. El conquistador maya encargado del gobierno externo de la ciudad está asociado con el águila, el sol, el día, el pedernal, la serpiente emplumada, la estación seca y el maíz maduro de la cose- 


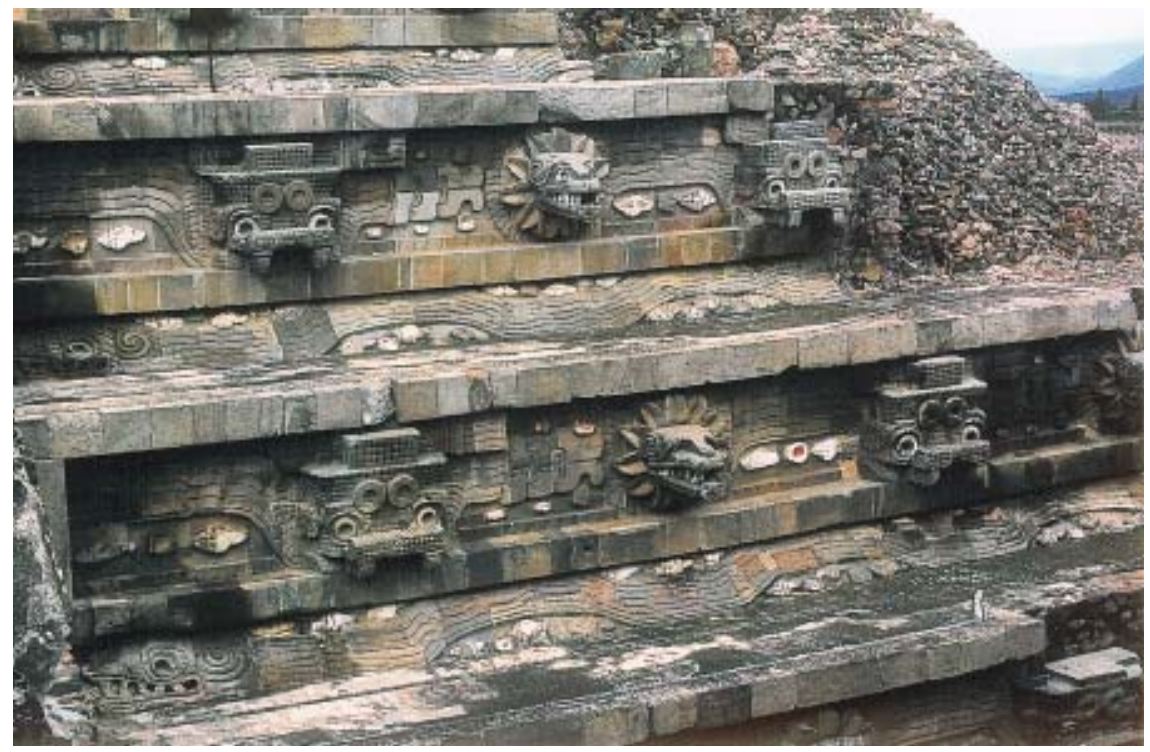

Figuras ga y ab. Estelas i y 3 , Xochicalco. Fotos: Pedro Cuevas, Archivo Fotográfico IIE-Unam. Figuras ioa y iob. "¿T láloc-T ierra?" Pirámide de Q uetzal cóatl, T eotihuacan. Fotos: M ichel

cha; el autóctono del altiplano mexicano, en cambio, está asociado con el jaguar, la tierra, Venus, la obsidiana, la serpiente-jaguar, la noche, la lluvia, la temporada de lluvias y la mata joven de maíz. Además, parece que el significado ideológico de varias fechas calendáricas (7 y 9 O jo de reptil, ${ }_{3} 3 \mathrm{C}$ aña, 4 M ovimiento, 3 Venado y tal vez i M alinalli ) puede explicarse a partir de datos del Posclásico tardío y hay indicios de que los autóctonos ya hablaban náhuatl en esta época. En la escena de batalla que parece ser a la vez histórica, mítica y ritual, oposiciones semejantes marcan paradójicamente la victoria de los autóctonos telúricos sobre los invasores solares mayas y la cosecha de estos últimos.

En Xochicalco, en la misma época, ${ }^{19}$ dos estelas bien conocidas ostentan también dos cabezas de serpientes contrastadas (figuras ga y $9 \mathrm{~b}$ ). U na de estas cabezas está acompañada del glifo 4 M ovimiento, otro nombre del sol, y tiene los ojos alargados como las serpientes diurnas del Templo M ayor. La

I9. En la pirámide de la Serpiente Emplumada de Xochicalco se encuentra también el topónimo "lugar de turquesa". 


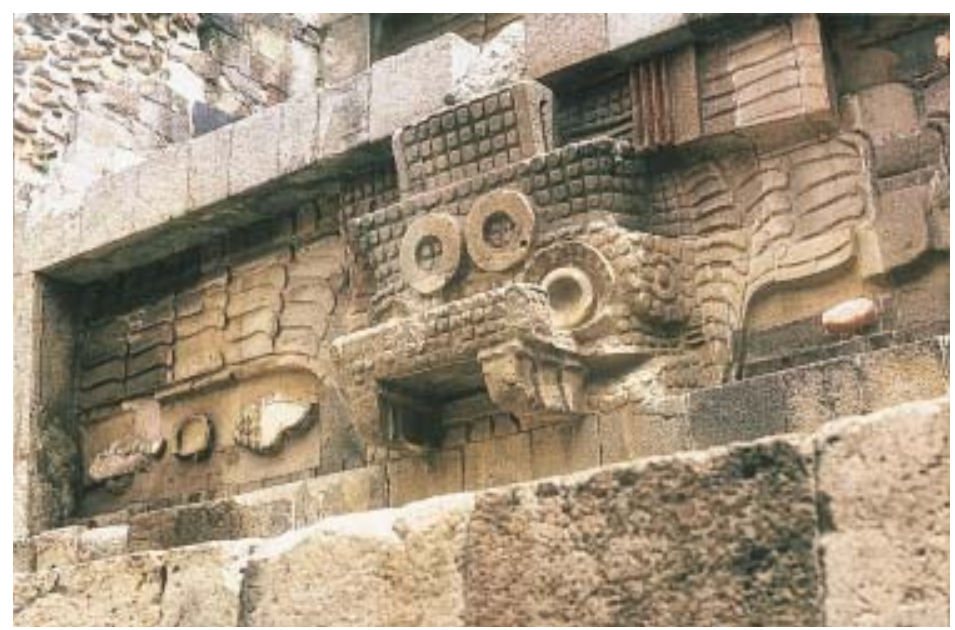

Figura iob.

otra, en cambio, tiene los ojos redondos como las serpientes de T láloc en Tenochtitlan. Esta segunda culebra está acompañada por el glifo 7 O jo de Reptil que designa, en Cacaxtla, al maíz.

Partiendo del estudio del simbolismo de las serpientes opuestas, diurnas y nocturnas, hemos observado una notable continuidad del Clásico, en Cacaxtla, al Posclásico, continuidad que resalta también del análisis de los rituales de las veintenas aztecas. A hora bien, la arqueología y la iconografía de C acaxtla atestiguan vínculos muy estrechos con Teotihuacan. Por lo tanto, debemos preguntarnos si en la gran metrópoli del valle de M éxico, que tanto inspiró a los aztecas, se encuentran también indicios de la existencia de una ideología similar.

Existe por lo menos un edificio, y uno de los más importantes, en el cual se encuentran, como en Tenochtitlan después, dos diferentes tipos de serpientes. Los tableros de la pirámide de Q uetzalcóatl están decorados con relieves de serpientes emplumadas cuyas cabezas resaltan en poderoso plano relieve, alternando con otras cabezas, más estilizadas y de forma geométrica, al otro extremo del cuerpo, cerca de los cascabeles (figuras ioa y iob). La identificación de la segunda cabeza ha dado lugar a muchas propuestas diferentes: T láloc, una mariposa (K rickeberg 1950: 310), una xiuhcoatl o serpiente de fuego (C aso y Bernal I952: IoI-II6), el monstruo telúrico cipactli (López Austin, López Luján y Sugiyama, 199I) y otras más. Recientemente Sugiya- 
ma (1989) sugirió, con escasa evidencia, que la cabeza era un tocado. Es cierto que en los murales de Tepantitla podemos observar un supuesto "tocado" sobre dos cuerpos de serpientes emplumadas entrelazadas, pero el parecido es vago. Además, la cabeza de forma geométrica no se encuentra en un lugar apropiado para un tocado y por lo tanto habría que explicar lo que significa este desplazamiento. Es verdad también que esta cabeza de forma geométrica se parece en algo a tocados figurando cabezas de animales, pero concluir que una cabeza es un tocado porque se parece a un tocado que representa una cabeza es un razonamiento perfectamente circular que no prueba mucho. ${ }^{20}$ También, Sugiyama habría podido comparar los relieves de los tableros de la pirámide con las pinturas de la pirámide en miniatura del "patio pintado" de Atetelco, donde se ven serpientes emplumadas enmarcando cabezas con elementos de Tláloc y otras con cabezas semejantes en el cuerpo (M iller 1973: ı64). Sea lo que fuere, lo que importa aquí es identificar la cabeza de forma geométrica. Para mí no hay duda de que se refiere a T láloc bajo su aspecto de dios de la tierra, aspecto macho del cipactli, como lo sugieren los círculos sobre la frente (recordemos que las serpientes-Tláloc del Templo M ayor de Tenochtitlan también Ilevan círculos-anteojeras sobre la cabeza; sabemos, por otro lado, que entre los aztecas llevar sólo las anteojeras era suficiente para asimilarse a T láloc: Sahagún, II, cap. 25, I950-8I, 2: 84); la "banda labial" de Tláloc; la forma de la cabeza que evoca algo el glifo del año tan frecuentemente asociado con el dios (compárese, por ejemplo, con el glifo en López Austin, López Luján y Sugiyama, I991, figura 3g); el nudo encima de la cabeza, nudo a veces asociado con los círculos sobre la frente ${ }^{21}$ (López Austin, López Luján y Sugiyama i99i, figura 6); las escamas que pueden remitir al cuerpo del saurio (cipactli) de la tierra, y, por supuesto, la asociación serpiente de plumas diurna-serpiente T láloc o serpiente jaguar telúrica nocturna entre los aztecas y en $C$ acaxtla.

Es cierto que, en Teotihuacan, hay menos oposición que unión de los dos términos, a pesar del hecho de que las dos cabezas se encuentren en las extre-

20. H ay que preguntarse también si todo lo que vemos sobre las cabezas de figuras en las pinturas o los relieves de T eotihuacan representa siempre verdaderos tocados, o si son conjuntos que contribuyen a precisar la identidad del personaje.

2I. En las urnas zapotecas, el nudo caracteriza también al dios del maíz (C aso y Bernal, 1952: IOI-II6), estrechamente vinculado con T láloc tanto entre los aztecas como entre los teotihuacanos (véase, por ejemplo, los murales del Pórtico 3 de Zacuala). 
midades opuestas del cuerpo de la serpiente. Pero hay que tomar en cuenta la ubicación de la pirámide, en la Ciudadela, a la cual se ha considerado como el centro político y religioso, situada en el corazón mismo de la ciudad, donde la avenida norte-sur cruza el eje este-oeste y el río San Juan. Un centro en el cual la pirámide se encuentra entre dos palacios que pueden ser los de los dos reyes de Teotihuacan, el solar ${ }^{22}$ y el nocturno-telúrico, como en Cacaxtla 0 en el Posclásico. U bicada entre los dos palacios de los reyes complementarios, la pirámide única (y probablemente con templo único también) con sus relieves insiste no sólo en la alternancia, sino también en la necesaria unión de los contrarios, de lo masculino y de lo femenino, de los agricultores y de los guerreros, de los dominados y de los dominadores $-y$, tal vez ya en esta época, de los autóctonos y de los recién llegados.\$

22. El hecho de que el sol parece estar casi ausente en la iconografía teotihuacana no debe llevar a conclusiones apresuradas: también en la pintura y escultura azteca, los dioses de la tierra, del maíz, etc., están mucho más presentes que H uitzilopochtli o que T onatiuh. 
DOI: http://dx.doi.org/10.22201/iie.18703062e.2001.79.2086

\section{6}

MICHEL GRAULICH

Bibliografía

Alvarado Tezozómoc, F., Crónica mexicana... precedida por el Códice Ramírez, M éxico, Ireneo Paz, I878.

1949 Crónica mexicáyotl, ed. y trad. de A. León, M éxico, U niversidad N acional Autónoma de México.

Arnold, P., Eating Landscape. Aztec and European $\mathrm{O}$ ccupation of T lalocan, N iwot, U niversity of Colorado, 1999.

Bierhorst, J., The M ythology of M exico and Central America, N ueva York, William M orrow, 1990.

Brundage, B. C., The Jade Steps, a Ritual Life of the Aztecs, Salt Lake C ity, U niversity of U tah Press, 1985.

Carmack, R. M., The Q uiché M ayas of U tatlan. The Evolution of a $\mathrm{H}$ ighland Guatemalan Kingdom, O klahoma, $\mathrm{N}$ orman, U niversity of O klahoma Press, $198 \mathrm{r}$.

Carrasco, D ., ed., To Change Place: Aztec C eremonial Landscapes, $\mathrm{N}$ iwot, U niversity Press of Colorado, 1991.

Caso, A. e I. Bernal, U rnas de 0 axaca, M éxico, Instituto $\mathrm{N}$ acional de Antropología e H istoria, 1952.

Códice Chimalpopoca:

I938 Die Geschichte der Königreiche von Culhuacan und M exiko, ed. y trad. de W. Lehmann, Stuttgart, W. Kohlhammer.

${ }_{1945}$ Códice Chimal popoca. Anales de Cuauhtitlan y Leyenda de los Soles, trad. de P. F. Velázquez, M éxico, U niversidad $\mathrm{N}$ acional Autónoma de M éxico.

1992 History and M ythology of the Aztecs. The Codex Chimalpopoca, 2 vols., ed. y trad. de J. Bierhorst, T ucson, U niversity of Arizona Press.

Códice Vaticano A o Ríos. Antigüedades de M éxico basadas en la recopilación de Lord Kingsborough, edición facsimilar comentada por J. Corona N úñez, 4 vols., M éxico, 1961-67, vol. 3.

Durán, fray D iego, $\mathrm{H}$ istoria de los indios de la N ueva España e I sas de la Tierra Firme, 2 vols., ed. de A. M. G aribay, M éxico, Porrúa, 1967.

Eliade, M ircea, Initiations, rites, sociétés secrètes, París, G allimard, 1959.

1965 Le sacréet le profane, París, G allimard.

1969 Le mythe de l'eternel retour. Archétypes et répétitions, París, Gallimard.

1970 Traité d'histoire des religions, París, Payot.

Garibay K., Á. M., Épica náhuatl, M éxico, Universidad N acional Autónoma de M éxico, 1964.

Graulich, M ., "Tlacaxipehualiztli ou la fête aztèque de la moisson et de la guerre", Revista Es pañola de Antropología Americana I2, 1982: 215-254.

1983 "Templo M ayor, Coyolxauhqui und C acaxtla", M exicon 5, i: 91-4. I990 M itos y rituales del M éxico antiguo, M adrid, I stmo.

I990b "D ualities in C acaxtla", M esoamerican D ualism, 46th International Congress of Ameri-

canists, Amsterdam, 1988, ed. de R. van Zantwijk e. a., U trecht, ruu: 94-II8.

1997 M yths of Ancient M exico, N orman, U niversity of O klahoma Press.

1999 Ritos aztecas, Las fiestas de las veintenas, M éxico, Instituto N acional Indigenista. 
DOI: http://dx.doi.org/10.22201/iie.18703062e.2001.79.2086

H istoria Tolteca-Chichimeca, ed. y trad. de P. Kirchhoff, L. O dena G üemes y L. Reyes G arcía, M éxico, Instituto $\mathrm{N}$ acional de Antropología e H istoria-CisinaH, 1976.

I chon, A., La religi on des T otonaques de la Sierra, París, editions du CNRs, 1969.

Krickeberg, W., "Bauform und W eltbilt im Alten M exiko", Paideuma 4, 1950: 295-333.

Kubler, G., "Eclecticism at C acaxtla", Third Palenque Round Table, 1978, 5, 2, Austin, University of Texas Press, 1980: 163-72.

Leyenda de los Soles, véase Códice C himal popoca.

López Austin, A., L. López Luján y Saburo Sugiyama, "T he Temple of Q uetzalcoatl at T eotihuacan: Its Possible I deological Significance", Ancient M esoamerica 2, 2, 1991: 93-I05.

$M$ atos $M$ octezuma, E., Vida y muerte en el T emplo M ayor, M éxico, 0 céano, 1986.

I988 The G reat T emple of the Aztecs: T reasures of Tenochtitlan, Londres, T hames \& H udson.

M iller, A., T he M ural Painting of Teotihuacan, W ashington, D umbarton 0 aks, 1973.

M olina, fray A. de, Vocabulario en lengua castellana y mexicana y mexicana y castellana, M éxico, Porrúa, 1970.

M uñoz Camargo, Diego, "D escripción de la ciudad y provincia de Tlaxcala”, Relaciones geográficas del siglo xvI: Tlaxcala, t. I, ed. de R. Acuña, M éxico, U niversidad N acional Autónoma de M éxico, 1984.

N owotny, K. A., "Rituale in M exiko und um N ordamerikanischen Südwesten", Jahrbuch für Geschichte von Staat, Wirtschaft und G esell schaft Latenamerikas 8, 1970: I-38.

Pasztory, E., "El arte mexica y la conquista española", Estudios de Cultura Náhuatl 17, 1984: IOI-24.

Polaco, Ó scar, "Los murales: una perspectiva biológica", Cacaxtla, el lugar donde muere la lluvia en la tierra, ed. de S. Lombardo de Ruiz, D. López de M olina, D. M olina Feal, M éxico, Instituto Nacional de Antropología e H istoria, 1986: 531-555.

Read, K. A., Time and Sacrifice in the Aztec Cosmos, Bloomington e Indianapolis, Indiana U niversity Press, 1998.

Rojas, Gabriel de, "D escripción de Cholula", Relaciones geográficas del siglo xvI: T laxcala, t. 2, M éxico, U niversidad $\mathrm{N}$ acional Autónoma de M éxico, 1985, 2: 121-45.

Ruiz de Alarcón, H ., T reatise on the H eathen Superstitions, ed. y trad. de J. R. Andrews y R. $\mathrm{H}$ assig $\mathrm{N}$ orman, Londres, U niversity of O klahoma Press, 1984.

Sahagún, fray B. de, Florentine Codex, General H istory of the Things of N ew Spain, trad. de A. J. O. Anderson y Ch. E. Dibble, I2 vols., Santa Fe, $\mathrm{N}$ ew M exico, The School of American Research and the U niversity of U tah, 1950-8I.

1997 Primeros M emoriales by Fray Bernardino de Sahagún, ed. y trad. de Thelma D. Sullivan, completado y revisado por H. B. N icholson., A. J. O. Anderson, Ch. E. Dibble, E. Q uiñones K eber y W. Ruwet, M adrid, N orman, U niversity of O klahoma Press, Real Academia de la $\mathrm{H}$ istoria, 1997.

Schultze Jena, L., Indiana II. M ythen in der M uttersprache der Pipil von Izalco in El Salvador, Jena, G . Fischer, 1935.

Seler, E., Gesammelte Abhandlungen zur Amerikanischen Sprach und Altertumskunde, 5 vols., Berlín, Asher und C 0., 1902-1923.

Sugiyama, S., "I conographic Interpretation of the T emple of Q uetzalcoatl at Teotihuacan", Mexicon II, 4, 1989: 68-74. 
DOI: http://dx.doi.org/10.22201/iie.18703062e.2001.79.2086

\section{8}

MICHEL GRAULICH

Taggart, James M ., N ahuatl M yth and Social Structure, Austin, University of Texas Press, 1983.

Tenayuca. Estudio arqueológico de la pirámide, M éxico, Instituto N acional de Antropología e H istoria, 1935 .

T eogonía e historia de los mexicanos. T res opúsculos del siglo xvı, ed. de A. M . Garibay K., M éxiCo, Porrúa, 1965.

Tezozómoc, F. Alvarado, véase Alvarado T ezozómoc, F.

Townsend, R. F., The Aztecs, Londres, Thames and H udson, 1992. 